Please cite this article as: T. Šuklje, M. Hamdy, C. Arkar, J.L.M. Hensen, S. Medved, An inverse modeling approach for the thermal response modeling of green façades, Appl. Energy. 235 (2019) 1447-1456. doi:10.1016/J.APENERGY.2018.11.066.

NOTE: This is a PDF file of an unedited manuscript that has been accepted for publication to Sustainable Cities and Society. Therefore, the information contained in this manuscript may change before publication.

\title{
An Inverse Modeling Approach for the Thermal Response Modeling of Green Façades
}

\author{
Tomaž Šuklje ${ }^{1 *}$, Mohamed Hamdy $^{2}$, Ciril Arkar ${ }^{1}$, Jan L. M. Hensen ${ }^{3}$, Sašo Medved ${ }^{1}$ \\ ${ }^{1}$ Laboratory for Sustainable Technologies in Buildings, Faculty of Mechanical Engineering, University of \\ Ljubljana, Aškerčeva 6, 1000 Ljubljana, Slovenia \\ ${ }^{2}$ Dep. of the Civil and Environmental Engineering, Norwegian University of Science and Technology, NO-7491 \\ Trondheim, Norway \\ ${ }^{3}$ Unit Building Physics and Services, Dep. of the Built Environment, Eindhoven University of Technology, PO \\ Box 513, 5600 MB Eindhoven, Netherlands
}

\begin{abstract}
Green façades or vertical greenery systems (VGSs) are continuously gaining attention among urbanists for improving the living comfort and energy efficiency in urban areas. However, modelling and simulating the thermal response of VGSs remains a research topic. This paper introduces a novel inverse modeling approach for modeling the thermal response of VGSs on building envelopes. The modelling approach considers the VGSs as a homogeneous layer with apparent thermo-physical properties. The approach optimizes the apparent thermo-physical properties by calibrating the inverse model using data generated by a detailed thermal response model of VGS or experimental data. It is shown that the predicted temperature of VGS deviates by less than $\pm 1.3{ }^{\circ} \mathrm{C}$, while the heat flux on the inner side of the building envelope deviates by less than $\pm 0.3 \mathrm{~W} / \mathrm{m}^{2}$ compared to the measured values.
\end{abstract}

Keywords: Vertical greenery systems, Evaporative cooling, Green façade, Climate adaptive building skins, Apparent thermo-physical properties 


\section{Highlights}

- A vertical greenery system was modeled as a homogeneous layer.

- An inverse thermal modeling algorithm, using genetic algorithms, was developed.

- Apparent thermo-physical properties were determined for the homogeneous layer.

- Apparent properties are developed as a function of sol-air temperature.

- The thermal response of vertical greenery system can be modelled using the heat diffusion equation.

*Corresponding author:

Tomaž Šuklje

tomaz.suklje@fs.uni-lj.si

\section{Introduction}

With rising global warming and urbanization, energy use for the cooling of buildings is expected to progressively increase in the future [1]. Researchers are constantly seeking new solutions and technologies to face emerging challenges. One way to address these rising issues is by applying greenery in an urban environment in the form of urban parks and forests [2]. Kong et al. [3] demonstrated that these measures can impact the reduction of mean radiant temperature in an urban environment as well as energy use for cooling. In the previous decade, it was ascertained that the integration of greenery on building envelopes can also address these issues to a certain degree [4]. Greenery can either be applied on the roofs or façades. The former, which are called green roofs, are increasingly applied to buildings [5,6]; the latter, named green façades or vertical greenery systems (VGSs), are currently a subject of intensive research in various areas of expertise: impact on the urban heat island mitigation [7] and energy use for heating and cooling [8,9], building materials [10], urban acoustics [11,12] and particle deposition potential $[13,14]$.

The cooling effect of VGSs is enabled due to the adaptive properties of greenery; adaptive shading, evaporative cooling, and absorption of solar radiation [15]. Installing VGS is thus a way of upgrading an existing building envelope from a passive to an adaptive building envelope. The field of adaptive building envelopes is a rapidly developing research area in building physics [16] as well as in building performance [17] with the active research 
community [18], in which researchers focus on research gaps of developing new approaches for thermal response modelling and performance characterization.

The review presented by Pérez et al. [19] showed that VGSs impact a reduction of energy use for cooling between $20 \%$ and $30 \%$ due to the reduced heat flux into the building. In addition, VGS can be used to cool the inlet ventilation air of local ventilation systems, where air temperatures at the façade's boundary can be reduced by up to $5 \mathrm{~K}$ [20]. Cameron et al. [21] reported that outdoor experiments are the most suitable method for the evaluation of the cooling potential of VGSs. However, to fully explore the overall cooling potential in buildings, the thermal response models of VGSs have been developed. These models of VGSs are either validated against experimental data to estimate reduced heat flux into the building [22,23], validated and coupled with building energy simulation (BES) tools [24], or coupled with BES tools and then validated with experimental data, as shown by Dahanayake and Chow [25]. The thermal response models of VGSs are commonly based on lumped-capacitance models, which were originally presented by Stec et al. [26], incorporating detailed [23] or simplified [27] evapotranspiration models. In addition, greenery properties are required as the model inputs; such as solar absorptivity, emissivity, vertical leaf area index (LAIV), view factors, resistance factors, and convective heat transfer coefficients [23]. The majority of the developed thermal response models utilize an assumed or referenced rather than measured values of the aforementioned properties; this is due to the complex and dynamic plant physiology and unforeseen events (plant diseases, injuries, etc.). Conclusively, (i) detailed models have assumed parameters and (ii) are difficult to integrate into BES.

Since the experiments are the best method for the evaluation of the thermal response of VGSs, as they take into account the dynamicity of plant physiology, and that thermal response models have several shortcomings, alternative approaches were introduced. It has been shown that a thermal response model of VGSs can be derived from the experimental data using statistical methods [15]. Olivieri et al. [28] developed an autoregressive model for the prediction of temperature difference of a wall module with and without greenery, based on the outdoor air temperature, relative humidity, and solar radiation. The results show that the model is suitable, although adjustments are needed for different types and states of plants. Similarly, Šuklje et al. [20] developed a multi-parametric model of air temperature in the air gap using net radiation heat flux instead of solar radiation. Even though the insights on the temperature reduction and air temperature in the building boundary with VGSs are valuable for the estimation of the impact of greenery on the building envelope and urban environment, it has limited usability in 
further analyses of the thermal response of buildings (BES tools) with greenery, as outdoor boundary conditions have to be assumed.

Alternatively, the in situ or laboratory experimental data of the building envelope thermal response can be used for the development of simplified physical models, which supplement complex physical phenomena. In state-of-the-art building envelopes, such as phase change material (PCM) integrated into building envelopes [29,30], complex physical phenomena can be modeled as a heat conduction problem, introducing apparent thermo-physical properties. In particular, the apparent heat capacity of the PCM is dependent on the temperature, as shown by Arkar and Medved [31]. The apparent heat capacity of the PCM can be determined using the inverse thermal modeling [32]. Moreover, inverse thermal modeling is also used in building physics for the determination of the effective thermo-physical properties of inhomogeneous materials [33] and wetted materials [34]. Hence, the approach is worth investigating for VGSs thermal response modeling. In addition, this approach seems to have extended usability in the context of data-driven thermal response models.

In the era of the Internet of Things (IoT), there is a strong trend in using a large number of sensors to acquire data and to generate valuable data insights. The IoT is also topical in the building sector, where it is reported that it can help to run building services more efficiently [35] and detect the impact of user behavior on indoor air quality [36]. That is also expected to be the case for the maintenance and performance monitoring of the VGS, since there is a strong trend in the establishment of VGS pilot projects [4], in which a large number of sensors are being implemented [37].

The paper aims to present a novel method, which responds to the highlighted research gaps of VGSs thermal response modeling and represents a future-proof approach, aligned with the IoT paradigm, for VGSs thermal response modeling based on big data, which is being generated in ongoing and new pilot projects and experimental setups. In essence, the proposed method simplifies complex physical models of interacting heat and mass transfer phenomena within VGS. The method is formulated as a heat conduction problem in a homogenous layer of a building envelope with apparent thermo-physical and radiative properties. The input for the method can be either experimental data or generated data from a validated detailed thermal response model of VGS. To the author's knowledge, such a method represents an innovation in the thermal response research of VGSs as well as the potential for wider use in future adaptive building envelope applications. Thermo-physical properties are derived in the form of the parametrical models considering independent variables in a form that can be easily used in well- 
established BES tools (e.g., EnergyPlus, IDA-ICE, etc.), standardized methods for the characterization of the dynamic properties of the building envelope and the low-order BES models. The latter are gaining momentum in the scientific community as well as applications as one of the most promising methodologies in the model predictive control [38].

\section{Methods}

In our previous study, referenced in [23], an experimental and detailed thermal response modeling study of VGS with vertical leaf area index (LAIV) equal to 6.1 and 7.2 was presented. It has been ascertained that VGS can cause up to $34 \mathrm{~K}$ lower surface temperatures of a façade, while maintaining air temperatures in the VGS' canopies close to ambient temperatures. Measured properties of the VGS were used as a basis as well as input for a detailed mathematical model of the thermal response of a building envelope with a VGS. The validated mathematical model was used for parametric analysis of the impact of thermal resistance of a building envelope on the cooling potential of the VGS. Conclusively, it has been ascertained that the thermal response modeling of VGS is complex due to the dynamic plant physiology, thermo-physical and radiative properties of VGS, which are difficult to determine due to the lack of experimental methods.

This study aims to simplify the thermal response modeling of VGS by modeling VGS as a homogenous layer of the building envelope as presented in Fig. 1. In that case, the greenery with supporting construction and air gap, enclosed by greenery and the building envelope, (Fig. 1.a) is substituted with a homogenous building envelope layer with the apparent thermophysical properties (Fig. 1.b). The apparent thermo-physical and radiative properties were determined using an inverse thermal modelling approach, as presented in the following section. 
(a)

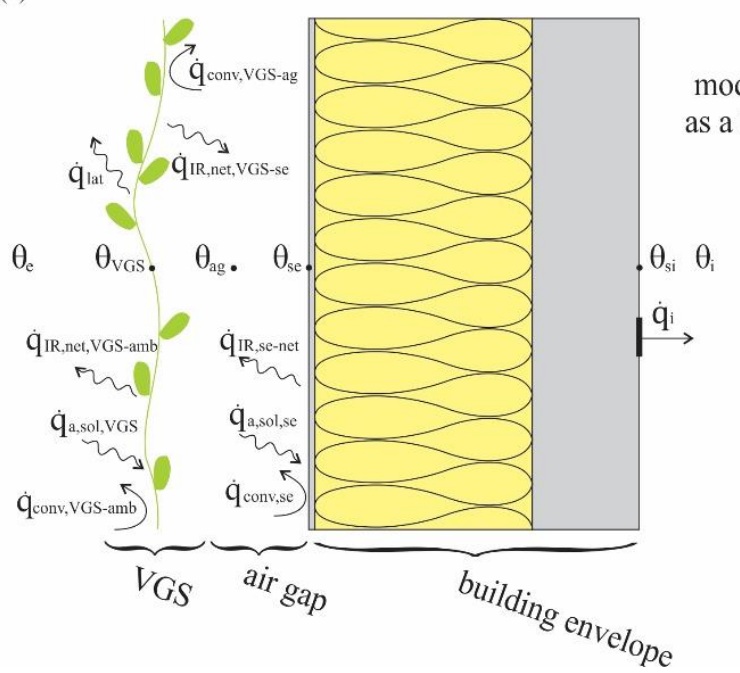

(b)

modeling of the VGS

as a homogenous layer

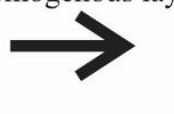

$\theta_{\mathrm{i}}$

$\theta_{\mathrm{e}}$

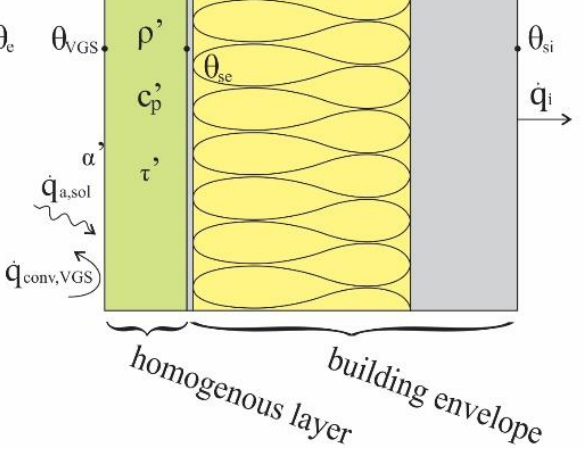

Fig. 1. The method proposes that heat and mass transfer in VGS (a) can be modeled as a homogenous layer $(b)$ of a building envelope with apparent properties; readers are referred to [23] for a detailed explanation of the presented boundary heat fluxes.

\subsection{Inverse thermal modeling}

Inverse thermal modeling is a method used for the determination of thermo-physical, radiative properties or boundary conditions in heat transfer problems. As these properties cannot be explicitly calculated, they must be assumed and then used for the calculation of the temperatures in the observed domain. The calculated temperatures are compared against control temperatures, which can be measured or calculated with validated models. The difference between the calculated and control temperatures is minimized by changing (guessing) the unknown properties in a systematic, iterative way, using either deterministic or nondeterministic methods. The unknown properties are suitable when the difference between the calculated and control data is below the desired value [39].

The inverse thermal modeling, as shown schematically in Fig. 3, is done so that the boundary conditions (Fig. 2), which include heat fluxes on both surfaces of a homogenous layer (marked green in Fig. 2), are used as inputs in a physical model of the homogenous layer. 


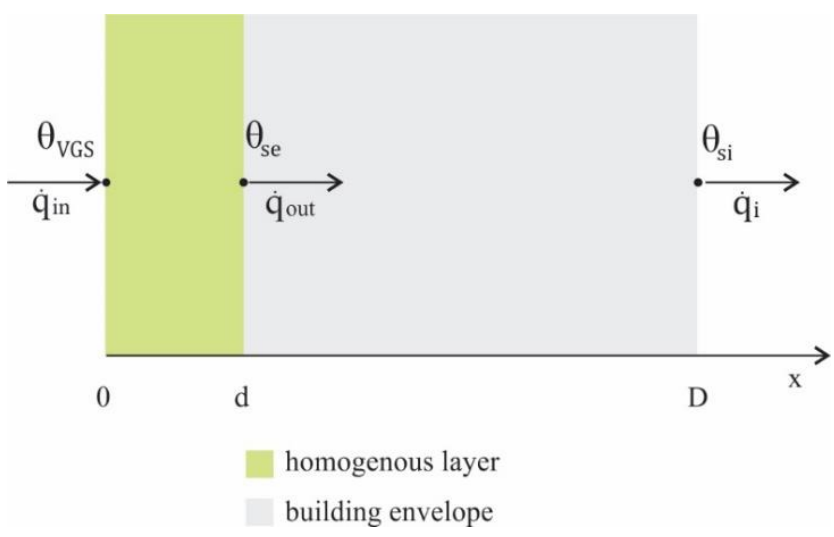

Fig. 2 Boundary conditions of the VGS as a homogenous layer.

The boundary conditions are calculated $\left(\dot{q}_{\text {in }}\right)$ using meteorological data (outdoor air temperature, relative humidity, global solar radiation and cloud coverage) and assumed constant values $\left(\varepsilon_{I R}, L A I V \ldots\right)$, and measured or generated with a validated thermal response model of VGS $\left(\dot{q}_{\text {out }}\right)$. Based on the initially assumed thermo-physical and radiative properties, temperatures within the homogenous layer are calculated. Further on, calculated temperatures are compared against control temperatures on the boundary of the homogenous layer, as shown in Fig. $2\left(\theta_{V G S}\right.$ and $\left.\theta_{s e}\right)$. The difference between temperatures is minimized by the means of the optimization problem of choosing optimal thermo-physical and radiative properties of the homogenous layer. In the study, inverse thermal modelling has been carried out using genetic algorithms (GA). The inverse modeling approach (Fig. 3) assumes a physical model (heat conduction), which is not necessarily the actual physical phenomena in the adaptive building envelope. Consequently, GA are more suitable for the search of the global minima, in comparison to the established deterministic methods used for inverse problems in building physics, which are more suitable for the search of local minima [40]. 


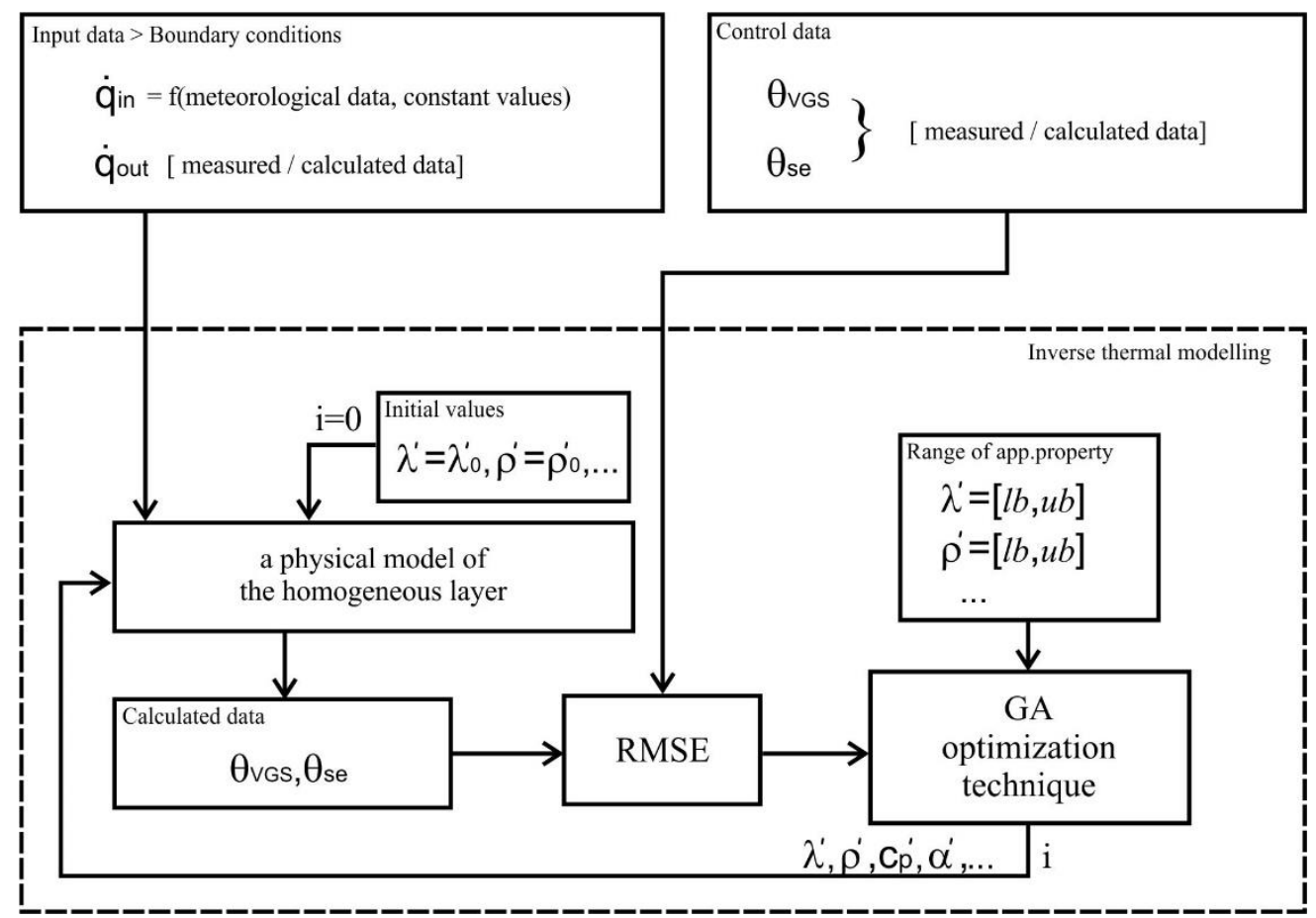

Fig. 3 A schematic diagram of the inverse thermal modeling approach developed for the determination of the apparent thermo-physical and radiative properties of the VGS; the inverse thermal modeling is shown for each (one) time step; the same schematic also applies for the entire time range.

\subsection{The method for verification of the inverse thermal modeling approach}

To determine the apparent thermo-physical and radiative properties, which reflect the impact of the meteorological data, the inverse thermal modeling approach (described in the previous section) has to be repeated numerous times. Doing so, it has been determined that a method is needed to guide the inverse thermal modeling and to evaluate whether the determined apparent thermo-physical and radiative properties are suitable. For this purpose, a three-step method has been developed:

1. In the first step, a suitable range of an individual apparent property $\chi_{i}$ is determined, which is represented by the lower $l b$ and the upper bound $u b$. Inverse modeling is carried out for each time step of the entire time range $t$. For $l$ time steps and $k$ apparent properties, a $l \times k$ matrix is retrieved. The suitability of the range is evaluated with statistical methods, i.e., the median and mean, which are calculated for each apparent 
property $\chi_{i}$. The lower $l b$ and upper $u b$ bound are suitable when the median $(\sim)$ and mean (-) value are approximately equal $\tilde{\chi}_{i} \approx \bar{\chi}_{i}$; that is for each apparent property $\chi_{i}$. An iterative procedure is carried out within the first step of the method, following these substeps:

(i) an initial range of each apparent property can be estimated based on the predominant material thermo-physical and radiative properties of the adaptive building envelope,

(ii) for the initially chosen range, apparent properties are determined if the condition is not met; the range must be widened (lower $l b$ and higher $u b$ ) and inverse modeling reinitiated; the sub-step is repeated several times, combining all apparent properties,

(iii) if the wider range does not result in met conditions, an additional apparent property can be added to the inverse model, and the iteration procedure is initialized again (sub-step (i)),

(iv) if precedent sub-steps do not lead to the solution, the assumed physical model has to be changed and the iteration procedure repeated for a new set of apparent properties.

2. In the second step, the dependence of the apparent thermo-physical and radiative properties on the independent variables (e.g. meteorological data) is investigated. Based on the results from the analysis, a desired functional equation of each apparent property is proposed.

3. In the last step, parametrical models of apparent properties are determined. The range of parameters in the parametrical model is chosen with respect to the range of each apparent property, $l b$ and $u b$, determined in the first step of the method. The chosen functions are then included in the inverse model in which parameter values are determined for the entire time range $t$. The inverse thermal modeling in this step can be repeated several times, using a different set of functions. As a result, a parametrical model with a smaller value of the objective function is chosen, which enables the best match of calculated and control temperatures.

The developed method is used in a case study of a homogeneous layer, which substitutes VGS, shown below. First, the control and input data for the inverse thermal modeling were prepared. Based on the experimental data analyses and test runs, a suitable model of the homogeneous 
layer was proposed, as presented in Section 2.4. The developed method was then applied, and the results are presented and discussed in Section 3.

\subsection{Input and control data}

The input and output data for the inverse thermal modeling can be obtained either experimentally or numerically, with a detailed thermal response model. In the current study, the input and control data have been generated using the validated thermal response model of the indirect VGS, which has been installed at the outdoor test facility of the University of Ljubljana, Slovenia. The development and validation of the thermal response model of VGS have been described in detail in the previous study [23]. For the purpose of better understanding and development of the physical model of the homogenous layer, the most important information on the VGS is as follows. In the study, a Phaesolous Vulgaris plant was used with a measured transmissivity $\tau_{V G S}$ of 0.09 and LAIV of 7.2. It has also been ascertained that the transmissivity is independent of the meteorological parameters. In addition to the measured radiative properties of VGS, the model has been developed assuming solar absorptivity of 0.768 and longwave emissivity of 0.983 . The irrigation of the greenery has been automated to ensure maximal required water for evapotranspiration, thus ensuring the validity of the evapotranspiration model.

The validated thermal response model of VGS, considering the modifications presented below, is used together with climatic data from the test reference year (TRY) for Ljubljana, Slovenia. The generated control and input data cover the expected range of meteorological conditions in summer, which, in our case, is wider than the available experimental data.

In comparison with the measured longwave radiation in a previous study [23], the net radiation heat flux in the current study is given by the following equation, considering $\beta$ to be equal $90^{\circ}$ for vertical surfaces:

$$
\dot{q}_{I R, n e t}=\varepsilon_{I R} \sigma \frac{1-\cos \beta}{2}\left(T_{V G S}^{4}-T_{s u r r}^{4}\right)+\varepsilon_{I R} \sigma \frac{1+\cos \beta}{2}\left(T_{V G S}^{4}-T_{s k y}^{4}\right)
$$

In the study, it is considered that surrounding surfaces (surr), encountered in radiative heat exchange, have the same temperature as the ambient air [41]. The sky temperature $\theta_{s k y}$ is 
calculated according to the cloud coverage factor $c_{c}$ and empirical relations for the emissivity of the sky $\varepsilon_{s k y}[42]$.

$$
\begin{aligned}
& \varepsilon_{s k y}=0.711+0.005 \theta_{d e w}+0.73\left(\frac{\theta_{d e w}}{100}\right)^{2} \\
& \theta_{s k y}=\theta_{e}\left(\varepsilon_{s k y}+0.8\left(1-\varepsilon_{s k y}\right) c_{c}\right)^{\frac{1}{4}}
\end{aligned}
$$

The interior surface boundary condition equation is as follows:

$$
-\lambda \frac{\partial \theta}{\partial x}=\dot{q}_{i}=h_{s i}\left(\theta_{s i}-\theta_{i}\right) \quad ; x=D, \quad t>0
$$

The indoor air temperature is considered to be constant at $25^{\circ} \mathrm{C}$. Convective heat transfer coefficient on the interior surface $h_{s i}$ of the building envelope, taking convective and longwave radiation heat transfer into account, is assumed to be equal to $7.7 \mathrm{~W} /\left(\mathrm{m}^{2} \mathrm{~K}\right)$.

The control and input data were generated with the validated VGS thermal response model, for the period from $1^{\text {st }}$ July to $31^{\text {st }}$ August. In Fig. 4., the control data are presented for the first week in August. The control data cover temperatures in two nodes; the surface temperature of the VGS $\theta_{V G S}$ and the surface temperature of the building envelope $\theta_{s e}$.

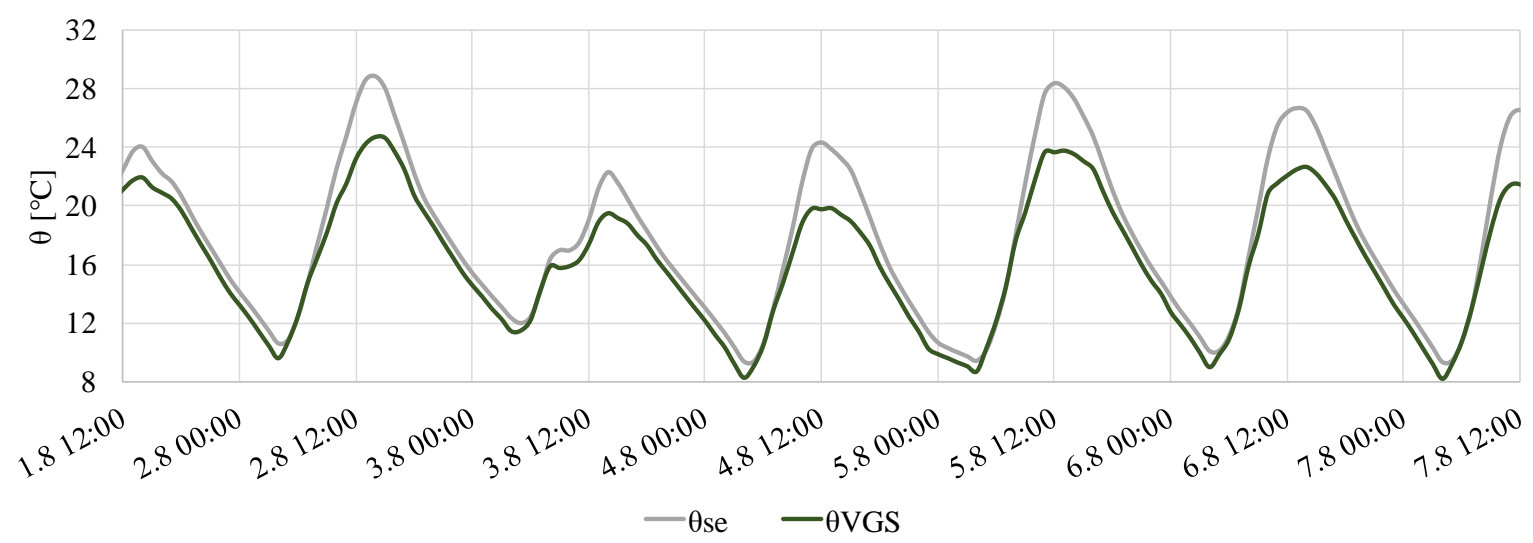

Fig. 4 Generated control data for the inverse thermal model using the validated VGS thermal response model.

2.4 The physical model of the homogenous layer 
The central part of the inverse thermal modeling approach is a physical model of the homogenous layer. It has to be run numerous times to optimize suitable apparent thermophysical and radiative properties of the homogenous layer (as presented in Fig. 3). In the current study, the physical model of the homogenous layer is assumed to be a one-dimensional heat conduction problem. Thus solving the partial differential equation with corresponding boundary and initial conditions:

$$
\begin{array}{ll}
\frac{\partial}{\partial x}\left(\lambda^{\prime} \frac{\partial \theta}{\partial x}\right)+q_{g e n}^{\prime}=\rho^{\prime} c_{p}^{\prime} \frac{\partial \theta}{\partial t} & ; 0<x<d, t>0 \\
-\lambda^{\prime} \frac{\partial \theta}{\partial x}=\dot{q}_{\text {in }}(t) & ; x=0, t>0 \\
-\lambda^{\prime} \frac{\partial \theta}{\partial x}=\dot{q}_{\text {out }}(t) & ; x=d, t>0
\end{array}
$$

where $q_{g e n}^{\prime}$ is a general expression of the volumetric heat generation, which can be applied to an arbitrary part of the homogenous layer to take into account an actual physical phenomenon.

Eq. 5 has been solved by dividing the homogenous layer into $n$ sublayers as shown in Fig. 5 . Thus, the heat conduction problem is reduced to a set of ordinary differential equations, which were solved using the Matlab function ode15s [43]. In the current study, it has been confirmed that the homogenous layer can be divided into eleven sublayers.
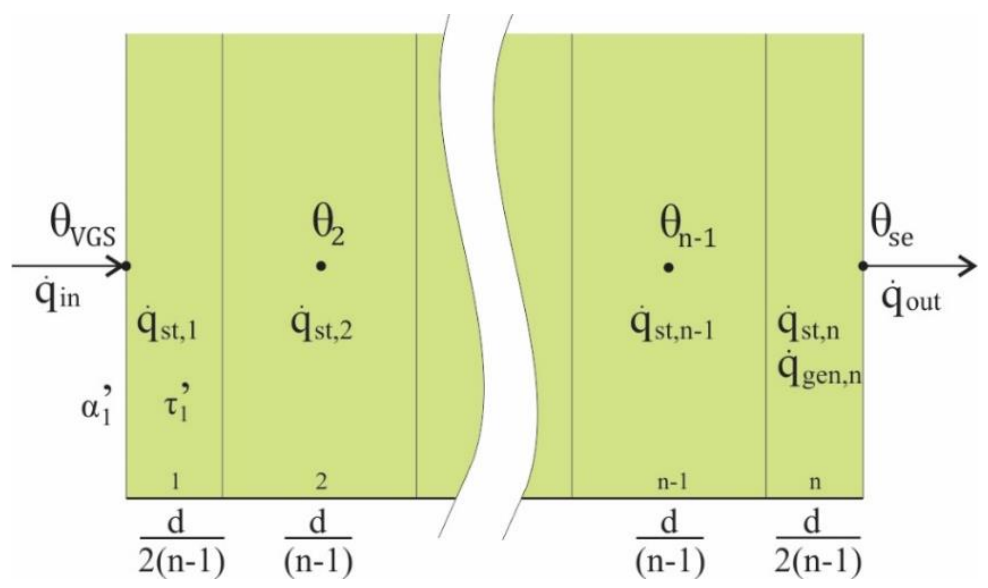

Fig. 5 Schematics of the homogenous layer with corresponding $n$ sublayers.

The physical model of the homogenous layer has been developed to fit the actual physical phenomena in VGS. Thus, it is considered that solar radiation is absorbed in the first and last 
sublayers (Fig. 5). The transmissivity of intermediate sublayers is assumed to be equal to 1 . That is due to the fact that the surface temperatures of the building envelope $\theta_{\text {se }}$ are the highest during the daytime (as seen in Fig. 4); therefore, the homogenous layer is also transparent. Thus, the physical model of the homogenous layer also considers the relation:

$$
\alpha^{\prime}+\rho^{\prime}+\tau^{\prime}=1
$$

as well as the following boundary conditions for the homogenous layer:

$$
\begin{aligned}
& -\lambda \frac{\partial \theta}{\partial x}=\dot{q}_{\text {in }}=\alpha^{\prime} G_{g l o b, 90}-\dot{q}_{I R, n e t}-\dot{q}_{c o n v} ; x=0, \quad t>0 \\
& -\lambda \frac{\partial \theta}{\partial x}=\dot{q}_{\text {out }} ; \quad x=d, \quad t>0
\end{aligned}
$$

Boundary conditions at the external surface of the homogenous layer are determined considering the same meteorological data as for the generation of the control and input data.

The convective heat transfer coefficient on the exterior surface of the homogenous layer $h_{c o n v}$ is assumed to be equal to the one at the VGS [23]. The thickness of the homogenous layer $d$ used in the study was considered constant at $0.2 \mathrm{~m}$. In the last sublayer, the entire transmitted solar radiation is absorbed ( $\alpha_{n}^{\prime}$ is equal to 1 ). The absorbed solar radiation is modeled as uniform heat generation by the following equation:

$$
q_{g e n, n}^{\prime}=\tau_{1}^{\prime} \alpha_{n}^{\prime} G_{g l o b, 90}\left(\frac{2(n-1)}{d}\right) ; \quad x=d, \quad t>0
$$

\section{Results and discussion}

Following the proposed methodology, presented in Sections 2.1 and 2.2, all three apparent thermo-physical properties of the homogeneous layer were included in the inverse thermal model: apparent thermal conductivity $\lambda^{\prime}$, apparent specific heat $c_{p}^{\prime}$, and apparent density $\rho^{\prime}$. The lower bound of the consecutive apparent properties has been assumed to be close to the prevailing material's thermo-physical properties (the air). The upper bound, however, has been defined much higher in order to take into account the latent heat of plants' evapotranspiration. Within an iterative procedure (step 1., sub-step iii), additional parameters have been added to the inverse thermal model: apparent absorptivity $\alpha^{\prime}$ and transmissivity $\tau^{\prime}$. 
Hourly values of the apparent thermo-physical properties from the first step of the inverse thermal modeling approach were analyzed in accordance with the developed methodology, calculating the mean and median values. The results are presented in Fig. 6 and in Table 1. The distribution of the data and, in particular, statistical indicators of each individual apparent thermo-physical property are shown on the suitability of the selected range (lower and upper bound) for apparent specific heat and apparent thermal conductivity. The mean and median values of the apparent density differ slightly more, although an appropriate range was selected.

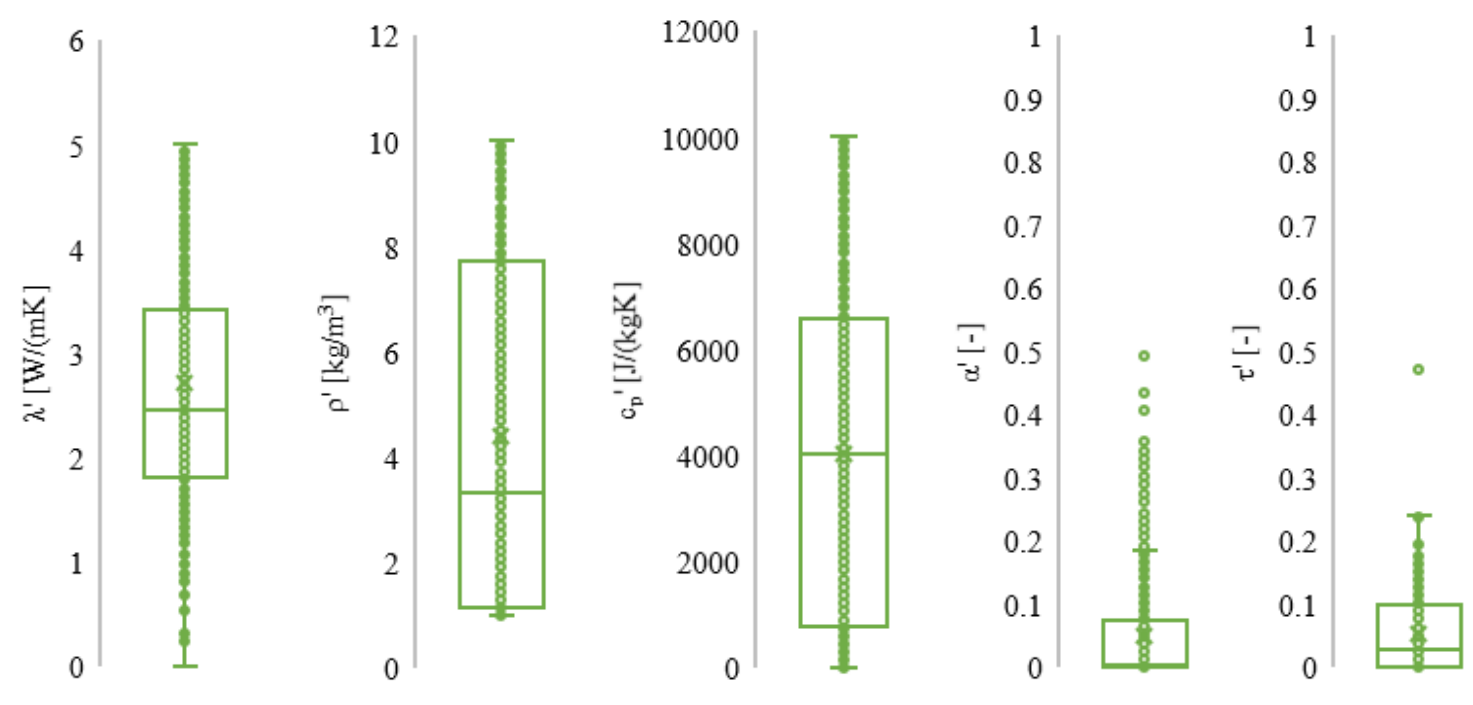

Fig. 6. The Box plots of consecutive apparent property, where mean is denoted as $\times$ and median as line within the box; the box represents the middle 50\% of sorted data; whiskers represent the upper and lower $25 \%$ of data; the lowest and the highest point $\left(^{\circ}\right)$ gives an indication of the selected $l b$ and $u b$ of each apparent property.

Table 1. Mean and median values obtained in the first step of the inverse modeling.

\begin{tabular}{lccccc}
\hline & $\lambda^{\prime}$ & $\rho^{\prime}$ & $c_{p}^{\prime}$ & $\alpha_{1}^{\prime}$ & $\tau_{1}^{\prime}$ \\
& {$[\mathrm{W} /(\mathrm{mK})]$} & {$\left[\mathrm{kg} / \mathrm{m}^{3}\right]$} & {$[\mathrm{J} /(\mathrm{kgK})]$} & {$[-]$} & {$[-]$} \\
\hline Mean & 2.72 & 4.4 & 4024 & 0.16 & 0.14 \\
\multirow{2}{*}{ Median } & 2.45 & 3.3 & 4019 & 0.02 & 0.10 \\
\hline
\end{tabular}

In Fig. 7, the variation of apparent thermo-physical properties for the first week in August is presented. Even though the lower quartile of apparent density (whiskers) in Fig. 6 is very narrow, the apparent density follows a graph pattern close to the apparent specific heat. Furthermore, $c_{p}^{\prime}$ has a narrower lower quartile, because $c_{p}^{\prime}$ values are close to $l b$ during nighttime (Fig. 7). 

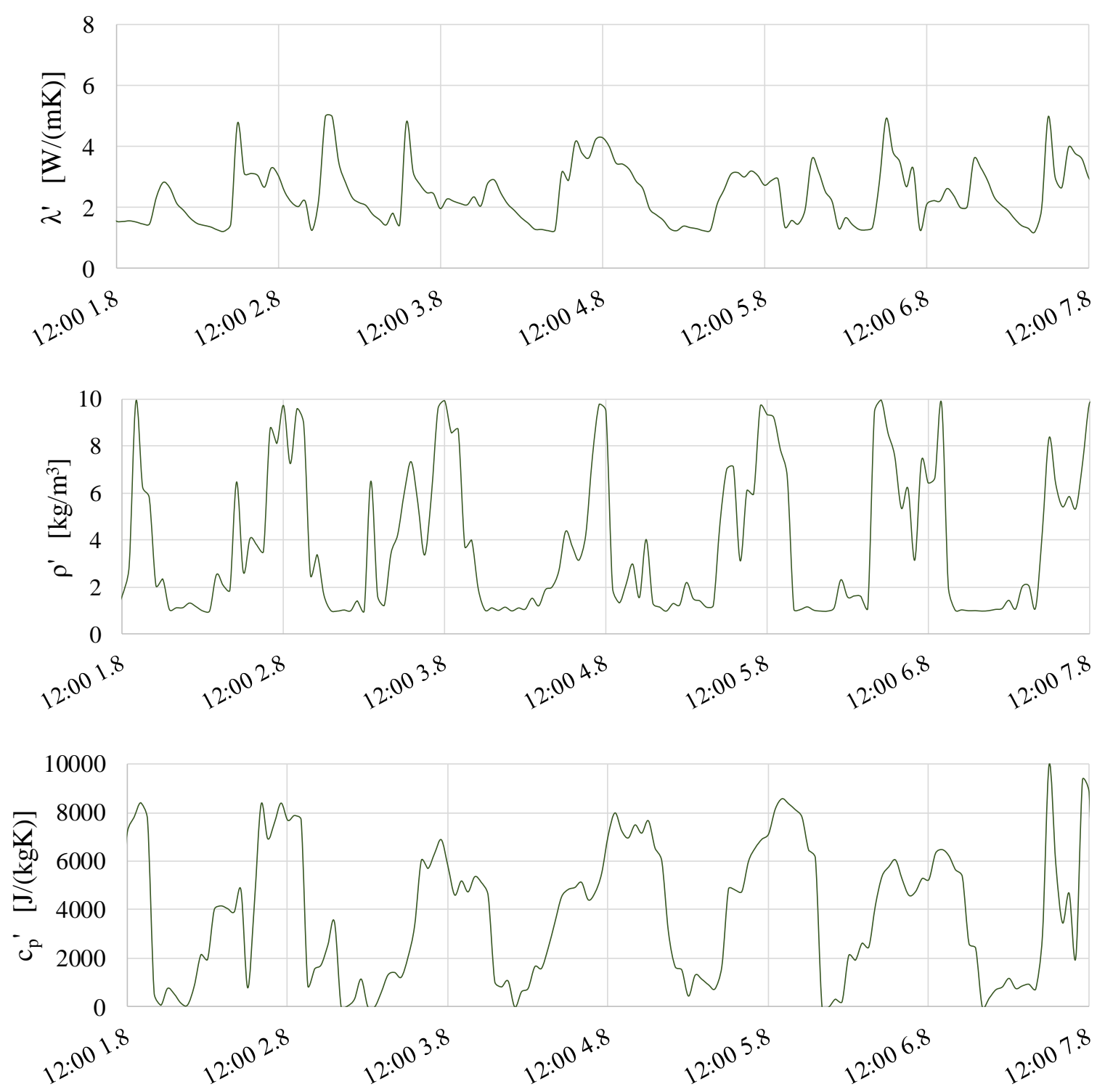

Fig 7. Hourly values of homogeneous layer's apparent thermo-physical properties determined within the first step of the inverse modeling.

Even greater discrepancies of the mean and median values were obtained for the apparent radiative properties: apparent absorptivity and transmissivity (Table 1, Fig. 8). The results presented in Fig. 8 reveal that, in the period of maximum heat load, the major part of the shortwave radiation is reflected from the exterior surface of the homogenous layer, as the $\alpha^{\prime}$ and $\tau^{\prime}$ are close to 0 . During the nighttime, the apparent absorptivity and transmissivity were set to zero because at that time the short-wave radiation equals zero. In addition, the uneven size of sections in box plot and outliers' data in Fig. 6 indicates that the apparent absorptivity and 
transmissivity are not to be set as variables in the homogenous layer model; instead, they should be set as constant values.

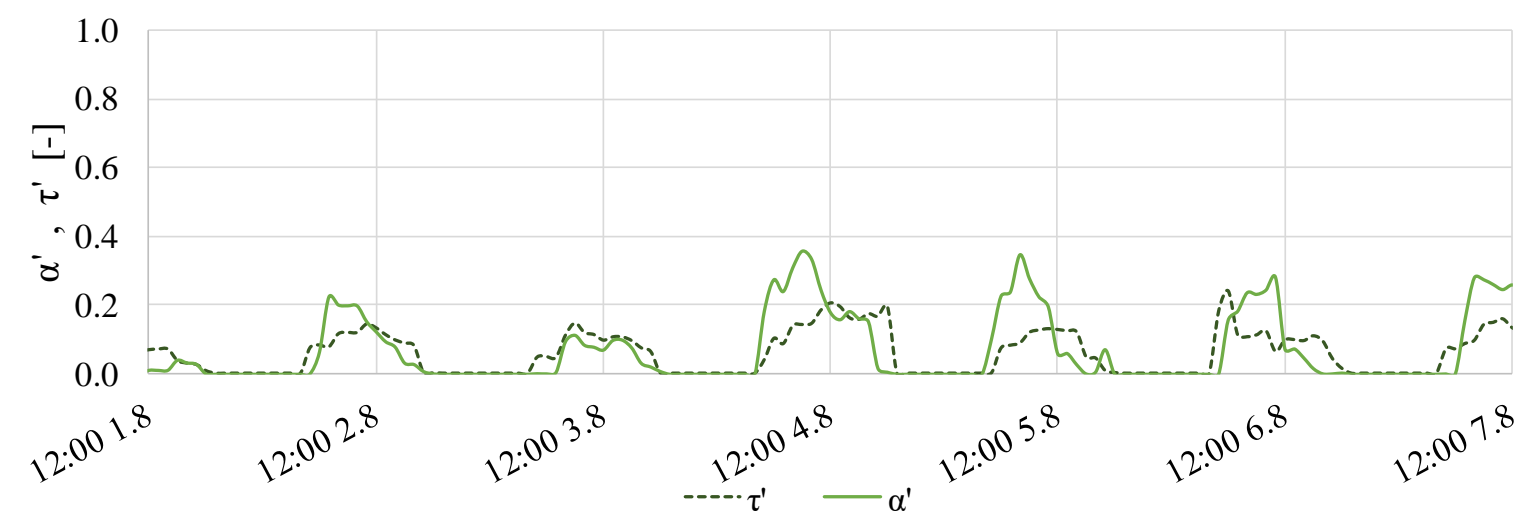

Fig. 8. Hourly values of homogeneous layer's radiative properties determined within the first step of inverse modeling.

Since all iterative steps (sub-step ii) have not been shown due to the extensive database of results, it is noteworthy that the additional widening of the range of apparent absorptivity and transmissivity would not improve the statistical indicators. Therefore, it is reasonable that these two properties of the homogeneous layer are modelled as constant values in the iterative substep iii and in subsequent steps (steps 2 and 3 of the inverse modeling).

Based on the statistical indicators, it has been ascertained that apparent density can be expressed as a functional equation. Thus, for apparent thermo-physical properties, a functional equation needs to be specified in step 2 of the inverse modeling process, which will include the most relevant meteorological parameters. In the previous studies, it was determined that besides net radiative heat flux, air temperature is the most influential, and in many cases exercised as the only independent variable to determine evapotranspiration rate $[44,45]$. Therefore, the relative humidity has not been considered as an independent variable in the inverse thermal modeling process. It has been determined that a sol-air temperature is the most appropriate parameter, as it is commonly used for evaluation of heat transfer through exterior surfaces and dynamic properties of the building envelope. The sol-air temperature is defined as:

$$
\theta_{\text {sol-air }}=\theta_{e}+\left(\frac{\alpha_{1}^{\prime} G_{g l o b, 90}-\dot{q}_{I R, n e t}}{h_{\text {conv }}}\right)
$$


The results of $2^{\text {nd }}$ step analyses showed that a linear parametric model should be proposed for apparent specific heat, density, and thermal conductivity:

$$
\chi=b_{\chi, 1}+b_{\chi, 2} \cdot \theta_{\text {sol-air }}
$$

Constant values $(\chi=b \chi, 1)$ for apparent absorptivity and apparent transmissivity, and a linear parametric model (Eq. 11) for apparent specific heat, apparent density, and apparent thermal conductivity were then included in the inverse model. Constants of the parametric functions that were obtained with the inverse modeling approach for the considered time range of two months are presented in Table 2.

Table 2. Constants of parametric functions of apparent thermo-physical and radiative properties of the homogeneous layer, which substitutes the VGS.

\begin{tabular}{lccccc}
\hline \multirow{3}{*}{ Constant } & $\lambda^{\prime}$ & $\rho^{\prime}$ & $c_{p}^{\prime}$ & $\alpha_{1}^{\prime}$ & $\tau_{1}^{\prime}$ \\
& {$[\mathrm{W} /(\mathrm{mK})]$} & {$\left[\mathrm{kg} / \mathrm{m}^{3}\right]$} & {$[\mathrm{J} /(\mathrm{kgK})]$} & {$[-]$} & {$[-]$} \\
\hline $\mathrm{b} \chi_{, 1}$ & 2.789 & 3.608 & 4208.6 & 0.093 & 0.164 \\
$\mathrm{~b} \chi, 2$ & 0.0565 & 0.167 & 249.25 & 0 & 0 \\
\hline
\end{tabular}

\subsection{Verification of the VGS model as substitute homogeneous layer}

To what extent the apparent properties of the homogeneous layer fit the actual thermal response of VGS was examined with a comparison of control temperatures $\left(\theta_{V G S}\right.$ and $\left.\theta_{s e}\right)$, generated with the validated VGS thermal response model, and the temperatures of the homogeneous layer at the same position. The latter temperatures were obtained with the numerical model presented in Section 2.3 and using apparent thermo-physical and radiative properties (Eq. 11 and Table 2). Temperatures are compared for the representative period in Fig. 9 and for the whole period from July to August in Fig. 10. 


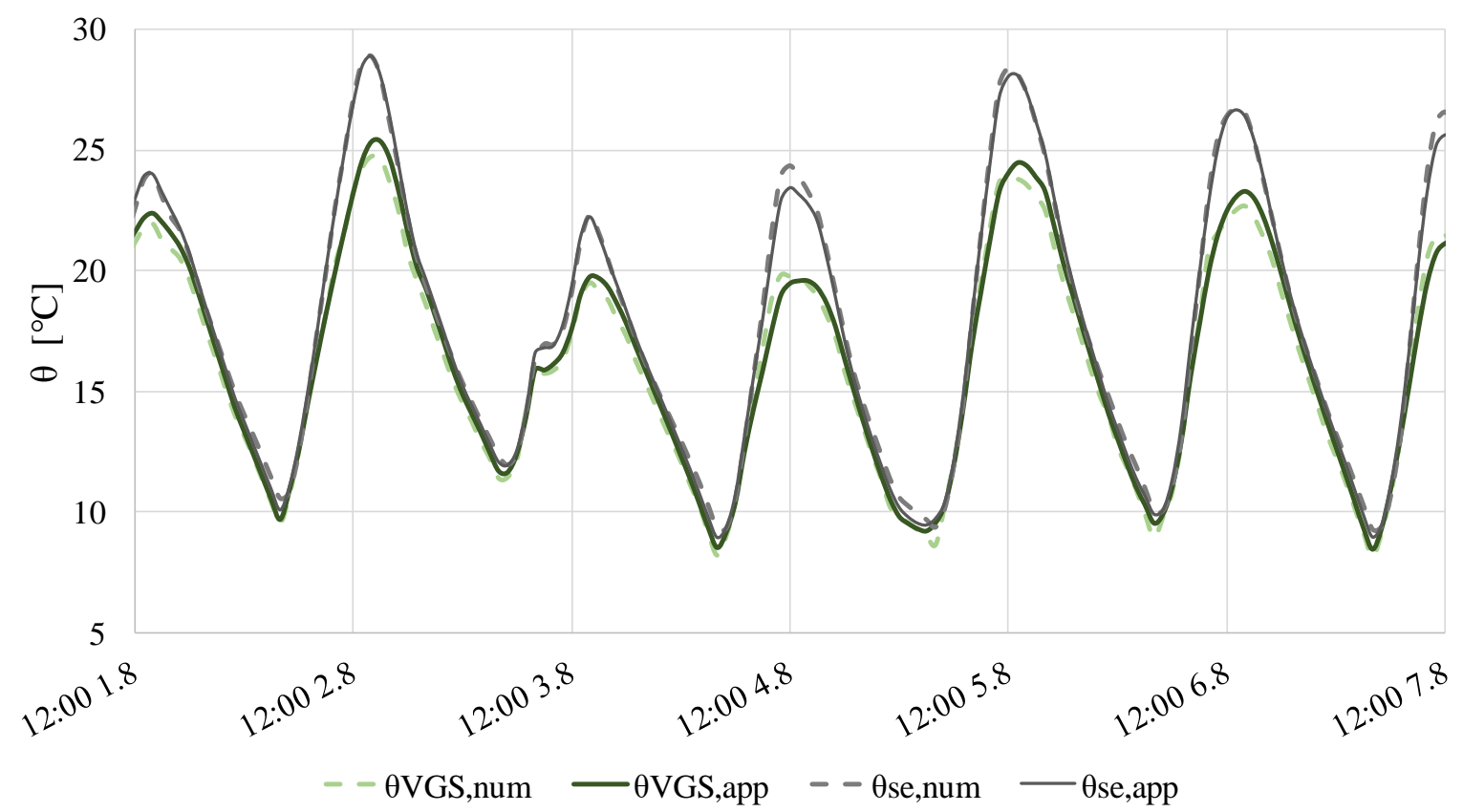

Fig. 9. Comparison of control temperatures (num) and temperatures at the boundary of the homogeneous layer, which substitutes VGS, obtained using apparent thermo-physical and radiative properties (app) in the chosen period.
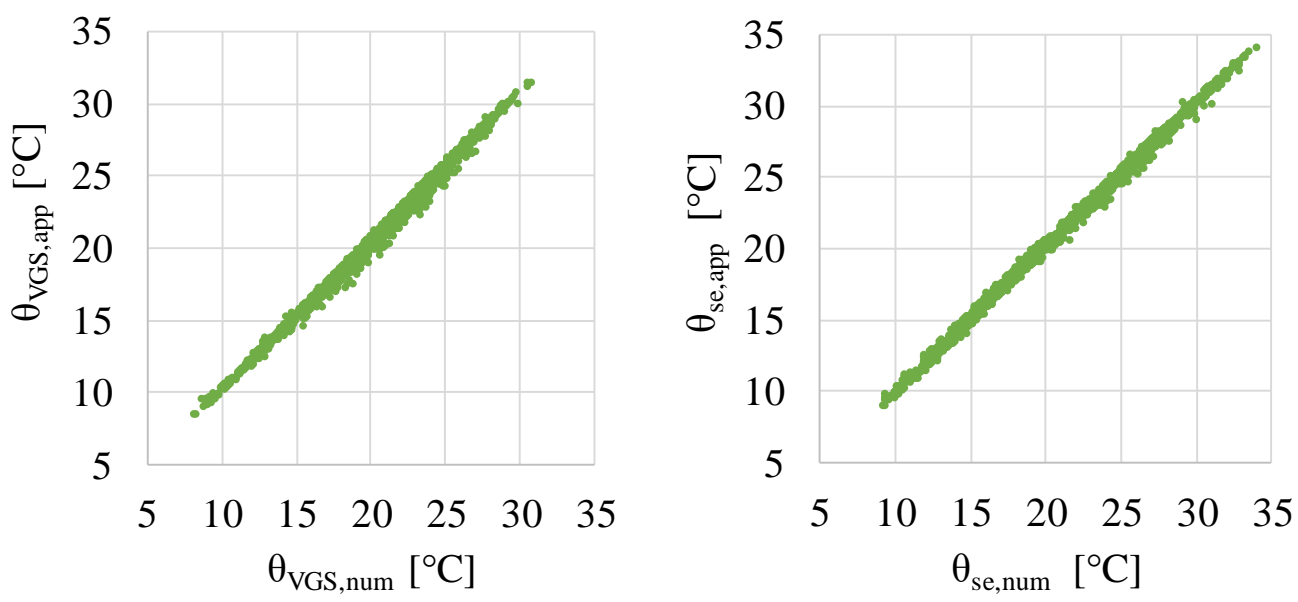

Fig. 10. Comparison of control temperatures (num) and temperatures at the boundary of the homogeneous layer, which substitutes VGS, obtained using apparent thermo-physical and radiative properties (app) for the whole period.

From the presented results, it can be concluded that temperatures deviate by less than $\pm 1.3{ }^{\circ} \mathrm{C}$, with a standard deviation equal to $0.3{ }^{\circ} \mathrm{C}$. Among the presented temperatures, the $\theta_{V G S}$ is of the particular interest in the context of the urban heat island mitigation analyses. For the calculation 
of the building energy demand or estimation of the cooling potential, the transient response of the $\theta_{s e}$ is important. It has been ascertained that utilizing the apparent properties' surface temperature of the building envelope deviates by no more than $\pm 1.1 \mathrm{~K}$, with standard deviation equal to $0.3 \mathrm{~K}$.

\subsection{Test of the apparent properties on different building walls with real meteorological data}

Furthermore, heat flux on the inner surface of the building envelope $\dot{q}_{i}$ using the validated numerical model and apparent properties of the homogenous layer is compared for wellinsulated $\left(\mathrm{U}=0.2 \mathrm{~W} / \mathrm{m}^{2} \mathrm{~K}\right)$ and moderately-insulated $\left(\mathrm{U}=0.5 \mathrm{~W} / \mathrm{m}^{2} \mathrm{~K}\right)$ building wall with seven days of meteorological data recorded at the test facility. The results in Fig. 11 show that heat fluxes differ with standard deviation equal to $0.1 \mathrm{~W} / \mathrm{m}^{2}$ and $0.3 \mathrm{~W} / \mathrm{m}^{2}$ for the well- and moderately insulated building walls, respectively. To the author's knowledge, this is the expected accuracy even for the thermal response modeling of a building wall without VGS due to the methodological simplifications or boundary conditions inside and outside the building using BES (e.g., TRNSYS, IDA ICE, etc.). Based on this comparison, it can be concluded that the apparent parametric properties of the homogeneous layer are appropriate.
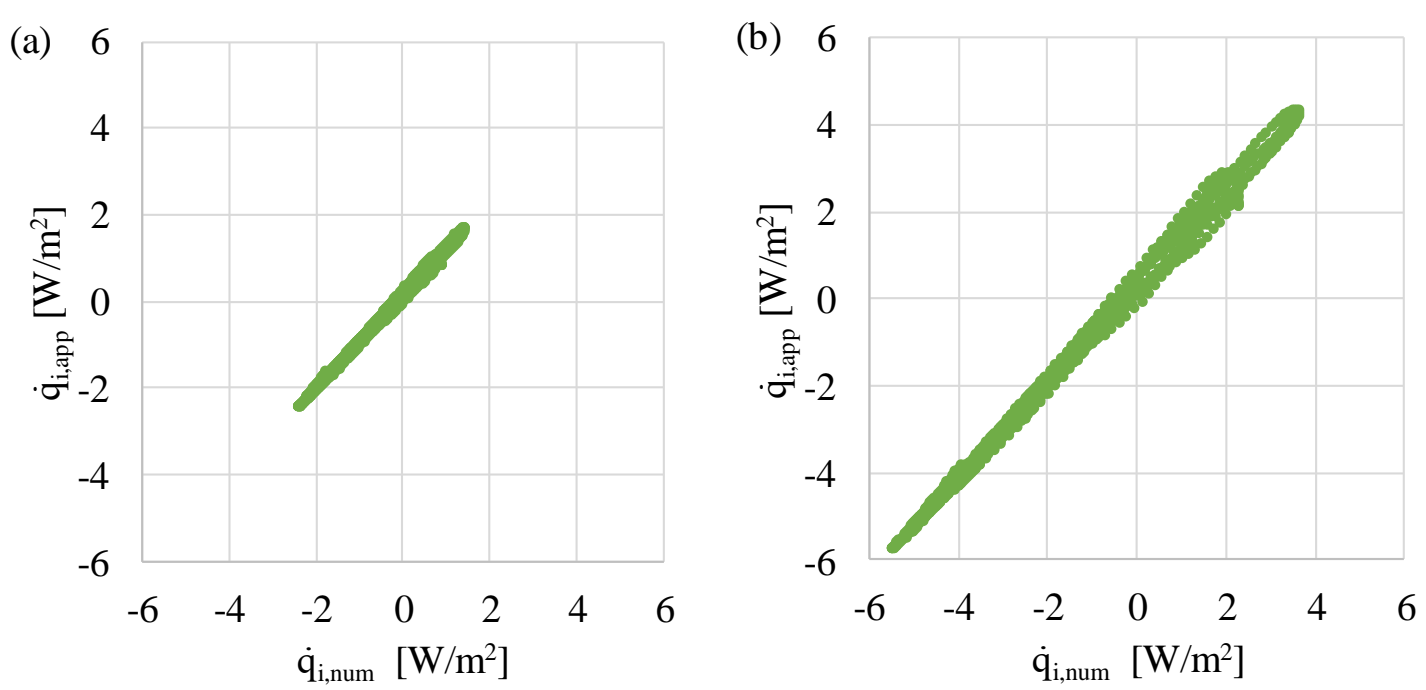

Fig. 11. Comparison of heat flux on the inner surface obtained with validated thermal response model of VGS (num) and the homogenous layer model with apparent properties (app); $U=0.2 \mathrm{~W} / \mathrm{m}^{2} K(a)$, $U=0.5 \mathrm{~W} / \mathrm{m}^{2} K(b)$.

\section{Conclusions}


Growing interest in VGSs and their complexity call for the simplification of thermal response modeling. Simplified VGS models enable their integration into available building performance simulation tools (e.g., EnergyPlus, IDA-ICE, TRNSYS, etc.), which help us to better understand VGSs' impact on the energy performance and thermal comfort in buildings. The presented study addresses this concern by proposing a novel methodology. In contrast to the established physical modeling of the VGSs' thermal response, the proposed methodology models a VGS as a homogenous layer. Consecutive steps of the inverse thermal modeling approach, which enable determination of the apparent thermo-physical and radiative properties of such layers, were proposed. As shown in the study, the apparent thermo-physical properties can be determined as a function of the sol-air temperature, which includes the main independent meteorological parameters. The verification of the methodology showed that the outer surface temperature of the homogeneous layer, representing the VGS temperature, which is significant for urban heat island mitigation analyses, deviates by less than $\pm 1.3^{\circ} \mathrm{C}$. Furthermore, heat flux on the inner surface of the building envelope calculated with the validated model and a homogenous layer with apparent properties has been compared. The results differ with standard deviation up to $0.3 \mathrm{~W} / \mathrm{m}^{2}$, which is considered to be satisfactory compared to results from established methods.

Even though the presented method is validated for subjected VGS in summer conditions, its objective is to be suitable for the use with arbitrary VGSs, especially the pilot projects, which are most commonly equipped with IoT technology. Utilizing the method that has been developed with big data, it is anticipated that seasonable effects, realistic conditions of soil moisture, plant physiology, and the radiative properties of VGSs can also be accounted for; however, additional parameters may need to be included in the model. Thus, having valuable insights into future VGSs' designs and maintenance approaches. In addition, the developed methodology is planned to be used with green roof thermal response modelling utilizing longterm in situ experimental results.

\section{Acknowledgments}

The authors would like to acknowledge the financial support provided by the Slovenian Research Agency within the research program P2-0223 (C) "Heat and Mass Transfer" and the networking opportunities given by the Cost Action TU1403 “Adaptive Façades Network”.

\section{References}


[1] A. Prieto, U. Knaack, T. Klein, T. Auer, 25 Years of cooling research in office buildings: Review for the integration of cooling strategies into the building façade (1990-2014), Renew. Sustain. Energy Rev. 71 (2017) 89-102. doi:10.1016/j.rser.2017.01.012.

[2] A.-S. Yang, Y.-H. Juan, C.-Y. Wen, C.-J. Chang, Numerical simulation of cooling effect of vegetation enhancement in a subtropical urban park, Appl. Energy. 192 (2017) 178-200. doi:10.1016/J.APENERGY.2017.01.079.

[3] F. Kong, C. Sun, F. Liu, H. Yin, F. Jiang, Y. Pu, G. Cavan, C. Skelhorn, A. Middel, I. Dronova, Energy saving potential of fragmented green spaces due to their temperature regulating ecosystem services in the summer, Appl. Energy. 183 (2016) 1428-1440. doi:10.1016/J.APENERGY.2016.09.070.

[4] R.A. Bustami, M. Belusko, J. Ward, S. Beecham, Vertical greenery systems: A systematic review of research trends, Build. Environ. 146 (2018) 226-237. doi:10.1016/J.BUILDENV.2018.09.045.

[5] C. Arkar, S. Domjan, S. Medved, Heat transfer in a lightweight extensive green roof under water-freezing conditions, Energy Build. 167 (2018) 187-199. doi:10.1016/J.ENBUILD.2018.02.056.

[6] S. Vera, C. Pinto, P.C. Tabares-Velasco, W. Bustamante, A critical review of heat and mass transfer in vegetative roof models used in building energy and urban enviroment simulation tools, Appl. Energy. 232 (2018) 752-764. doi:10.1016/J.APENERGY.2018.09.079.

[7] A. Afshari, A new model of urban cooling demand and heat island-application to vertical greenery systems (VGS), Energy Build. (2017). doi:10.1016/j.enbuild.2017.01.008.

[8] G. Pérez, J. Coma, S. Sol, L.F. Cabeza, Green facade for energy savings in buildings: The influence of leaf area index and facade orientation on the shadow effect, Appl. Energy. 187 (2017) 424-437. doi:10.1016/J.APENERGY.2016.11.055.

[9] E. Cuce, Thermal regulation impact of green walls: An experimental and numerical investigation, Appl. Energy. 194 (2017) 247-254. doi:10.1016/J.APENERGY.2016.09.079.

[10] A. Korjenic, J. Zach, J. Hroudová, The use of insulating materials based on natural fibers in combination with plant facades in building constructions, Energy Build. 116 (2016) 45-58. doi:10.1016/j.enbuild.2015.12.037.

[11] A.M. Lacasta, A. Penaranda, I.R. Cantalapiedra, C. Auguet, S. Bures, M. Urrestarazu, 
Acoustic evaluation of modular greenery noise barriers, Urban For. Urban Green. 20 (2016) 172-179. doi:10.1016/j.ufug.2016.08.010.

[12] G. Pérez, J. Coma, C. Barreneche, A. de Gracia, M. Urrestarazu, S. Burés, L.F. Cabeza, Acoustic insulation capacity of Vertical Greenery Systems for buildings, Appl. Acoust. 110 (2016) 218-226. doi:10.1016/j.apacoust.2016.03.040.

[13] K. Perini, M. Ottelé, S. Giulini, A. Magliocco, E. Roccotiello, Quantification of fine dust deposition on different plant species in a vertical greening system, Ecol. Eng. 100 (2017) 268-276. doi:10.1016/j.ecoleng.2016.12.032.

[14] A.J. Ghazalli, C. Brack, X. Bai, I. Said, Alterations in use of space, air quality, temperature and humidity by the presence of vertical greenery system in a building corridor, Urban For. Urban Green. 32 (2018) 177-184. doi:10.1016/J.UFUG.2018.04.015.

[15] T. Šuklje, S. Medved, C. Arkar, An Experimental Study on a Microclimatic Layer of a Bionic Façade Inspired by Vertical Greenery, J. Bionic Eng. 10 (2013) 177-185.

[16] R.C.G.M. Loonen, M. Trčka, D. Cóstola, J.L.M. Hensen, Climate adaptive building shells: State-of-the-art and future challenges, Renew. Sustain. Energy Rev. 25 (2013) 483-493. doi:10.1016/j.rser.2013.04.016.

[17] R.C.G.M. Loonen, F. Favoino, J.L.M. Hensen, M. Overend, Review of current status, requirements and opportunities for building performance simulation of adaptive facades, J. Build. Perform. Simul. 10 (2017) 205-223. doi:10.1080/19401493.2016.1152303.

[18] Adaptive facade network - Europe, COST, Delft, 2015.

[19] G. Pérez, J. Coma, I. Martorell, L.F. Cabeza, Vertical Greenery Systems (VGS) for energy saving in buildings: A review, Renew. Sustain. Energy Rev. 39 (2014) 139_ 165. doi:10.1016/j.rser.2014.07.055.

[20] T. Šuklje, C. Arkar, S. Medved, The local ventilation system coupled with the indirect green façade: a priliminary study, Int. J. Des. Nat. Ecodynamics. 9 (2014) 314-320. doi:10.2495/DNE-V9-N4-314-320.

[21] R.W.F. Cameron, J.E. Taylor, M.R. Emmett, What's 'cool' in the world of green façades? How plant choice influences the cooling properties of green walls, Build. Environ. 73 (2014) 198-207. doi:10.1016/j.buildenv.2013.12.005.

[22] I. Susorova, M. Angulo, P. Bahrami, Brent Stephens, A model of vegetated exterior facades for evaluation of wall thermal performance, Build. Environ. 67 (2013) 1-13. doi:10.1016/j.buildenv.2013.04.027. 
[23] T. Šuklje, S. Medved, C. Arkar, On detailed thermal response modeling of vertical greenery systems as cooling measure for buildings and cities in summer conditions, Energy. 115 (2016) 1055-1068. doi:10.1016/j.energy.2016.08.095.

[24] R. Djedjig, E. Bozonnet, R. Belarbi, Analysis of thermal effects of vegetated envelopes: Integration of a validated model in a building energy simulation program, Energy Build. 86 (2015) 93-103. doi:10.1016/j.enbuild.2014.09.057.

[25] K.W.D.K.C. Dahanayake, C.L. Chow, Studying the potential of energy saving through vertical greenery systems: Using EnergyPlus simulation program, Energy Build. 138 (2017) 47-59. doi:10.1016/j.enbuild.2016.12.002.

[26] W.J. Stec, A.H.C. van Paassen, A. Maziarz, Modelling the double skin façade with plants, Energy Build. 37 (2005) 419-427. doi:10.1016/j.enbuild.2004.08.008.

[27] K.J. Kontoleon, E.A. Eumorfopoulou, The effect of the orientation and proportion of a plant-covered wall layer on the thermal performance of a building zone, Build. Environ. 45 (2010) 1287-1303. doi:10.1016/J.BUILDENV.2009.11.013.

[28] F. Olivieri, D. Redondas, L. Olivieri, J. Neila, Experimental characterization and implementation of an integrated autoregressive model to predict the thermal performance of vegetal façades, Energy Build. 72 (2014) 309-321. doi:10.1016/j.enbuild.2013.12.062.

[29] Y. Cui, J. Xie, J. Liu, S. Pan, Review of Phase Change Materials Integrated in Building Walls for Energy Saving, Procedia Eng. 121 (2015) 763-770. doi:10.1016/j.proeng.2015.09.027.

[30] H. Akeiber, P. Nejat, M.Z.A. Majid, M.A. Wahid, F. Jomehzadeh, I. Zeynali Famileh, J.K. Calautit, B.R. Hughes, S.A. Zaki, A review on phase change material (PCM) for sustainable passive cooling in building envelopes, Renew. Sustain. Energy Rev. 60 (2016) 1470-1497. doi:10.1016/j.rser.2016.03.036.

[31] C. Arkar, S. Medved, Influence of accuracy of thermal property data of a phase change material on the result of a numerical model of a packed bed latent heat storage with spheres, Thermochim. Acta. 438 (2005) 192-201. doi:10.1016/j.tca.2005.08.032.

[32] Y. Cascone, Estimation of the Thermal Properties of PCMs through Inverse Modelling, Energy Procedia. 78 (2015) 1714-1719. doi:10.1016/j.egypro.2015.11.275.

[33] S.T. Nguyen, A.D. Tran-Le, M.N. Vu, Q.D. To, O. Douzane, T. Langlet, Modeling thermal conductivity of hemp insulation material: A multi-scale homogenization approach, Build. Environ. 107 (2016) 127-134. doi:10.1016/j.buildenv.2016.07.026.

[34] J.C. Damfeu, P. Meukam, Y. Jannot, E. Wati, Modelling and experimental 
determination of thermal properties of local wet building materials, Energy Build. 135 (2017) 109-118. doi:10.1016/j.enbuild.2016.11.022.

[35] M. Molina-Solana, M. Ros, M.D. Ruiz, J. Gómez-Romero, M.J. Martin-Bautista, Data science for building energy management: A review, Renew. Sustain. Energy Rev. 70 (2017) 598-609. doi:10.1016/J.RSER.2016.11.132.

[36] A. Martín-Garín, J.A. Millán-García, A. Baïri, J. Millán-Medel, J.M. Sala-Lizarraga, Environmental monitoring system based on an Open Source Platform and the Internet of Things for a building energy retrofit, Autom. Constr. 87 (2018) 201-214. doi:10.1016/J.AUTCON.2017.12.017.

[37] L. Nagle, S. Echols, K. Tamminga, FOOD PRODUCTION ON A LIVING WALL: PILOT STUDY, J. Green Build. 12 (2017) 23-38. doi:10.3992/1943-4618.12.3.23.

[38] M. Killian, M. Kozek, Ten questions concerning model predictive control for energy efficient buildings, Build. Environ. 105 (2016) 403-412. doi:10.1016/j.buildenv.2016.05.034.

[39] M.N. Ozisik, H.R.B. Orlande, Inverse Heat Transfer, Taylor \& Francis, New York, 2000.

[40] S. Wang, X. Xu, Parameter estimation of internal thermal mass of building dynamic models using genetic algorithm, Energy Convers. Manag. 47 (2006) 1927-1941. doi:10.1016/j.enconman.2005.09.011.

[41] F. Zanghirella, M. Perino, V. Serra, A numerical model to evaluate the thermal behaviour of active transparent façades, Energy Build. 43 (2011) 1123-1138. doi:10.1016/j.enbuild.2010.08.031.

[42] TRNSYS 17, (2015).

[43] Matlab 2014b, (2014).

[44] V. Mohammad, Temperature analysis of reference evapotranspiration models, Meteorol. Appl. 22 (2014) 385-394. doi:10.1002/met.1465.

[45] A. Rahimikhoob, Estimation of evapotranspiration based on only air temperature data using artificial neural networks for a subtropical climate in Iran, Theor. Appl. Climatol. 101 (2010) 83-91. doi:10.1007/s00704-009-0204-z.

\section{Nomenclature}

$c_{c} \quad$ cloud coverage factor (-) 


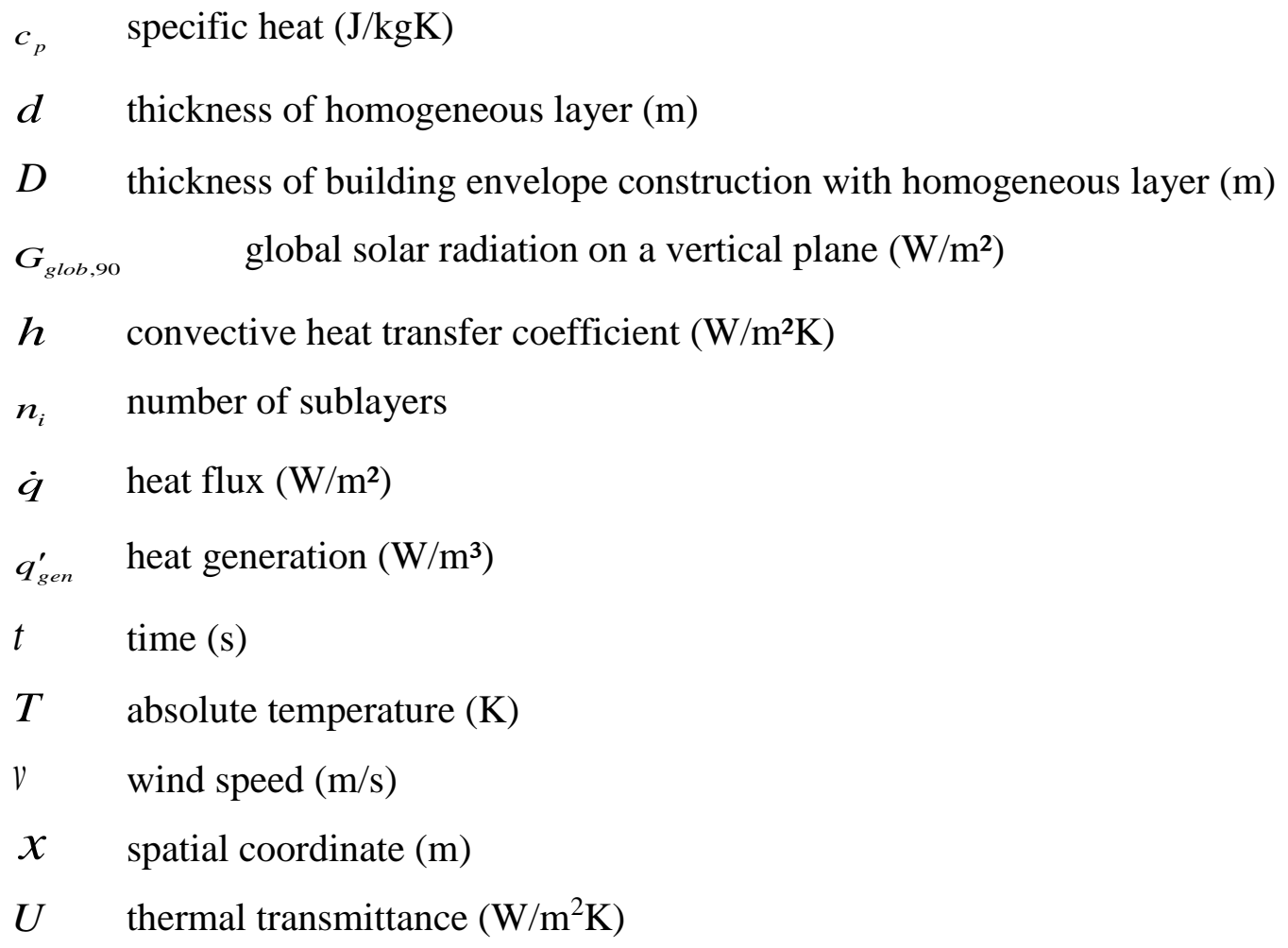

Greek symbols

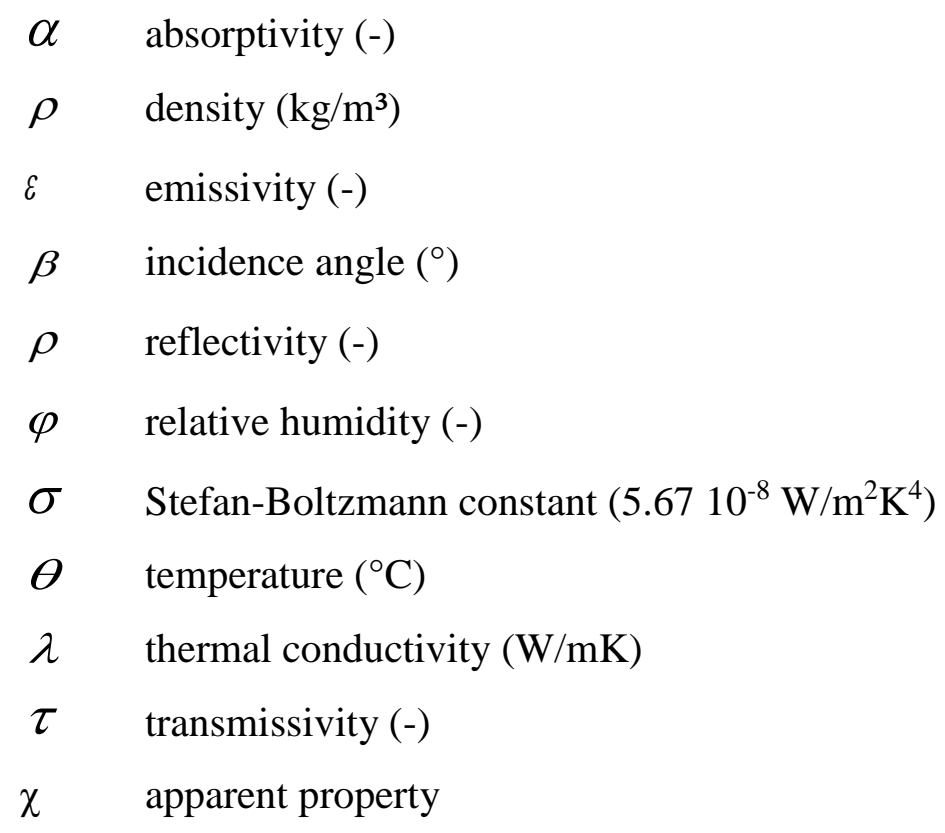




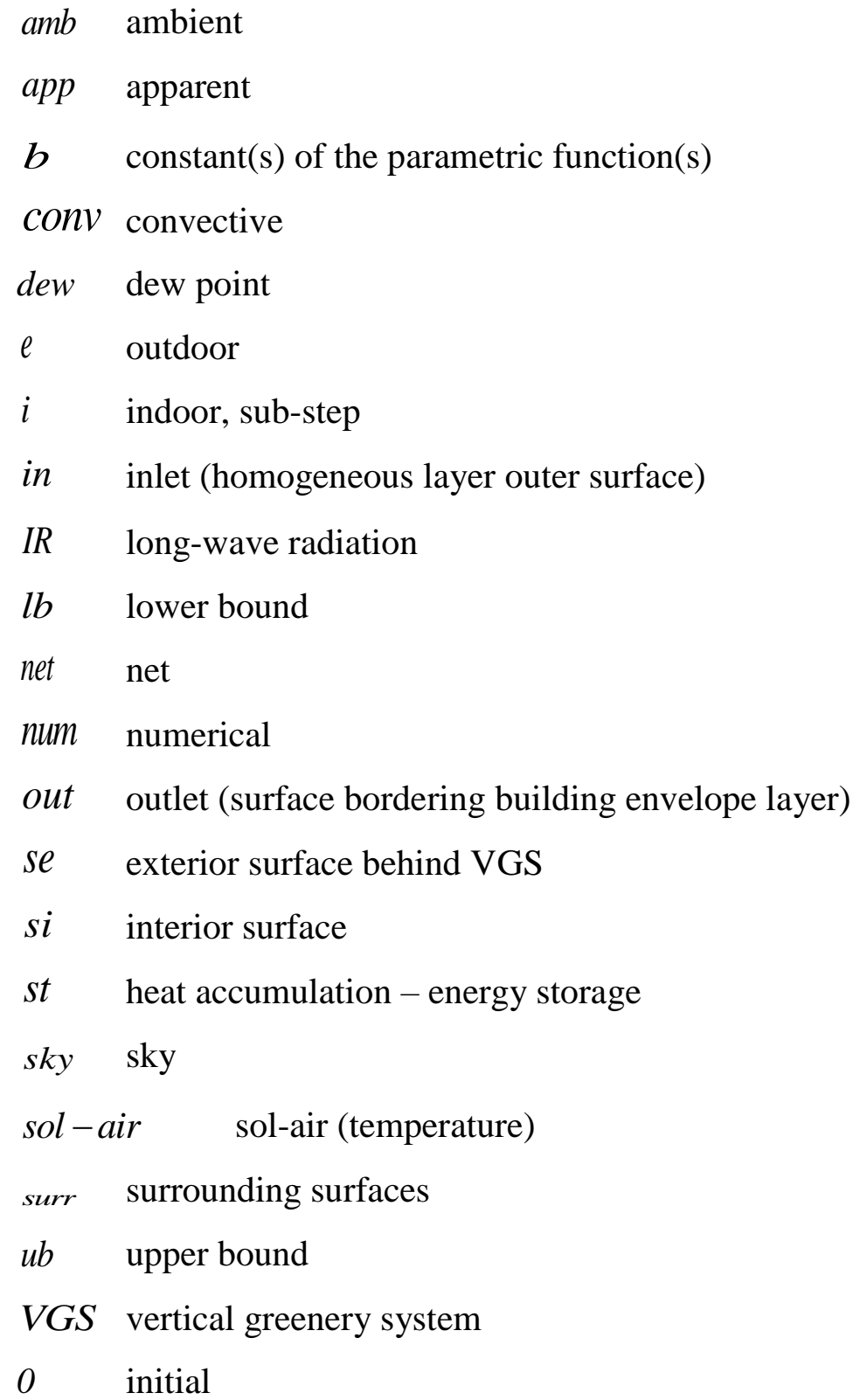

